\title{
PERCEPÇÃO AMBIENTAL: CONSCIÊNCIA E ATITUDE EM ESCOLAS DO ENSINO FUNDAMENTAL DO MUNICÍPIO DE JABOTICABAL (SP)
}

\author{
Baltasar Fernandes Garcia Filho ${ }^{1}$ \\ Ismail Barra Nova de Melo² \\ Silvio César Moral Marques ${ }^{3}$
}

Resumo: A relação entre homem e ambiente manifesta-se através dos seus sentidos e da sua cultura, por isso, os indivíduos possuem percepções diferentes. Durante um tempo de convivência num determinado espaço as pessoas tomam conhecimento dos objetos que estão no entorno e atribuem valores de acordo com suas necessidades e interesses. A percepção ambiental desenvolve uma consciência e no decorrer desse processo novas situações são percebidas. Vários processos perceptivos resultam em atitudes controladas pela cultura. O objetivo deste trabalho foi identificar como alunos de duas escolas públicas situadas no município de Jaboticabal-SP percebem a interação entre o ambiente rural e urbano e quais ações são feitas frente aos problemas ambientais. Foi aplicado um questionário junto aos alunos e as respostas foram discutidas frente ao referencial teórico concernente a percepção ambiental. Os resultados demostraram que os alunos possuem percepções diferentes. Prevaleceu em ambos os sexos uma visão superficial do ambiente, onde a natureza é reconhecida pela sua estética. Outro ponto relevante foram as respostas relacionadas às atitudes dos alunos, uma vez que a maioria das suas justificativas aponta os resíduos domiciliares como o principal problema ambiental.

Palavras-chave: Percepção Ambiental; Consciência; Atitude.

${ }^{1}$ Universidade Federal de São Carlos: baltazarfilho@terra.com.br

2 Universidade Federal de São Carlos: ismail@ufscar.br

${ }^{3}$ Universidade Federal de São Carlos: silviocmm@ufscar.br 


\section{Introdução}

A relação entre homem e ambiente manifesta-se através dos seus sentidos e da sua cultura. A experiência humana é o início para compreender o ambiente. Conviver no mundo permite ao homem conhecer os objetos que estão a sua volta atribuindo-lhes importância e significado. Dessa forma, são definidas suas escolhas, juntamente com a sua cultura durante as suas vivências e experiências, como a criação de regras que servem para manter a organização social. Isso significa que nessa relação entre os homens e as coisas do mundo os sentidos são, em primeiro lugar, o início para reconhecer o ambiente e, concomitantemente a este processo, se faz necessário o mapeamento mental que está relacionado à capacidade do homem de dar soluções aos problemas, de resgatar as suas lembranças, de fazer uso da linguagem, raciocinar e imaginar e desenvolver suas atividades mentais.

O homem ao se apropriar da realidade no qual vive pode intervir com ações que tragam benefícios para o meio ambiente, como conservar a biodiversidade, promover a justiça social entre os povos, distribuir a riqueza entre os países, cuidar da água como fonte de vida, entre tantas outras condutas que buscam equilibrar a relação da sociedade com a natureza. Para tanto, é necessário mudar sua atitude. A percepção ambiental também pode colaborar no contexto de outras abordagens, como no planejamento urbano, no sentido de integrar os ambientes naturais e construídos para melhorar a qualidade de vida das pessoas, perceber o autêntico sentido de pertencimento das pessoas, em relação ao lugar onde vivem, e demonstrar os valores ambientais de um determinado espaço, quando o mesmo é visto apenas como uma área turística que traz benefícios à economia. Para realizar esse trabalho levantamos algumas questões importantes, como distinguir a percepção de ambiente dos alunos e saber quais intervenções são realizadas em defesa de um ambiente mais equilibrado. Assim, nossa intenção é mostrar os valores que são atribuídos ao ambiente no qual vivem, as atitudes e a relação entre o espaço natural e urbano e se estes aspectos juntos desenvolvem uma consciência mais abrangente do meio ambiente.

\section{A experiência do lugar}

Para explicar as relações entre os indivíduos e o seu lugar, quer dizer, onde vivem em um determinado espaço, várias obras se fundamentam nas categorias de análise da Geografia. A paisagem e o lugar são conceitos geográficos usualmente empregados para investigar essa relação entre 0 homem e o meio ambiente. Segundo Holzer (2006) paisagem e lugar não têm o mesmo significado apesar de algumas obras colocarem-nos em posição semelhantes como na A Morfologia da Paisagem de Carl Suaer. Para Holzer (2006) as características da paisagem e do lugar estão sobrepostas e os objetos pertencentes ao espaço podem ser interpretados de perspectivas diferentes. 
De acordo com Tuan (2013) é através da experiência que o homem constrói a sua realidade, no qual as emoções humanas atribuem ao pensamento perspectivas diferentes de compreensão do mundo. As sensações como o calor e frio são qualificadas pelo pensamento, quer dizer, o calor é sufocante, a dor é aguda, o lugar simboliza tristeza ou alegria. O homem no decorrer da vida é submetido às situações desconhecidas e se arrisca ao enfrentar o perigo do novo, para aprender com base na própria vivência. "[...] Experiência é um termo que abrange as diferentes maneiras por intermédio das quais uma pessoa conhece e constrói a realidade" (TUAN, 2013, p.17). E para realizá-la a maioria dos homens faz uso dos cinco sentidos (visão, audição, olfato, paladar e tato) para entender e compreender a realidade.

O espaço vivido é um recorte espacial caracterizado pela cultura que o cerca, influenciando as pessoas e que por sua vez também o influenciam. Desse modo, advêm uma troca de experiência, quando existe um envolvimento do ser no mundo, um sentimento de pertencimento, sem interferência de um mundo exterior como chama a atenção Holzer "[...] Este complexo, se alienado ou distorcido por modas sociais ou intelectuais, se tornaria um não-lugar (Placelessness) ligado à inauticidade" (HOLZER, 2006, p.120).

De acordo com Tuan (2013) a visão do homem é o sentido mais importante para organização do espaço e os outros sentidos expandem-no, demonstrando uma constância na comunicação e expressão durante o olhar. Os lugares e os objetos representam o espaço, atribuindo-o personalidade de acordo com sua arquitetura. A sensação humana estimula a percepção sobre o ambiente e "[...] só depois da sensação é que acontecem a percepção e a cognição. Os processos sensoriais são, digamos assim, o início do ambiente para cada um de nós" (PINHEIRO, p.2006, p.67).

Segundo Pinheiro (2006) a percepção do espaço pelo indivíduo excede os processos mentais em reconhecer os objetos atribuindo-o significado, pois nada ou ninguém deve ser isolado do ambiente. Assim, a consciência de cada indivíduo é o resultado das sensações sobre o ambiente organizado pelos sistemas que compõem os sentidos humanos, reconhecendo o ambiente como um todo:

Convém ter em mente a afirmação de que a natureza e a sociedade funcionam holisticamente, pois os fatos e fenômenos se processam conjuntamente; um é causa de um efeito, que se torna, por sua vez, causa e efeito, dependendo do foco e do interesse que temos no momento (OLIVEIRA; MACHADO, 2004, p.133).

Desse modo, a natureza, as coisas e as ações executadas pelos indivíduos estão inter-relacionadas e perceber o ambiente não é o suficiente, é necessário conhecê-lo, o que acaba por originar um processo cognitivo. A interação entre os objetos e os indivíduos concebe à experiência o que em outras palavras significa atribuir valores as coisas do mundo de acordo com as necessidades e os interesses de cada um. A importância que damos ao manter 
as águas dos rios despoluídas, de preservar e conservar as áreas verdes, de cuidar dos bosques urbanos, como também usufruir de uma educação com qualidade, uma saúde pública mais humana, está ligado aos valores que atribuímos às coisas ponderados pelos filtros culturais.

\section{Percepção ambiental}

Vimos que a percepção é um processo mental que atribui valores aos objetos de acordo com as necessidades e interesses de cada indivíduo juntamente com a sua cultura. Durante um tempo de convivência no ambiente as pessoas tomam consciência em relação às coisas e mudam a realidade por intermédio das suas atitudes. "[...] $A$ percepção ambiental se distingue da percepção de objetos, pelas condições de 'imersão' do percebedor no tempo e no espaço do ambiente percebido" (PINHEIRO, 2006, p.68).

De acordo com Oliveira e Machado (2004) para avançar na compreensão da relação homem e meio ambiente é necessário considerar três princípios. O primeiro é a função da biodiversidade, florestas e os serviços ecossistêmicos que são prestados para a provisão de alimentos, água potável, madeira e fibras, energia e regulação climática. O segundo é a estrutura que compreende a interação do ambiente físico com uma comunidade englobando a mesma dimensão da função. O terceiro princípio é a transformação e diz respeito à estabilidade e a dinâmica dos processos entre os seres vivos e o seu meio físico.

Os estudos sobre percepção ambiental nos auxiliam a compreender as atitudes dos indivíduos no ambiente no qual vivem, ou seja, como agem em favor de melhorar a sua vida e daqueles que estão no seu entorno, como também permite identificar os valores atribuídos aos recursos naturais. Em ambientes onde as características físicas são diferentes, como o rural e o urbano, as atitudes são influenciadas pelo espaço físico e no decorrer da vida construímos relações com o ambiente ao qual contém matas, construções humanas e rios e as atitudes mudam conforme nossas experiências:

Para ilustrar como a atitude em relação a natureza pode mudar com o tempo, consideramos a montanha. Nas primeiras etapas da história humana, a montanha foi vista com assombro. Ela eleva-se das planícies habitadas; era remota, difícil de se aproximar, perigosa e inassimilável às necessidades do trabalho diário do homem (TUAN, 1980, p. 81)

Atualmente as montanhas são exploradas, contempladas, algumas ainda apresentam biomas exuberantes e para algumas culturas em seus picos estão as respostas mais procuradas pelos seres humanos. O que mudou dessas primeiras etapas para os dias atuais é que a ideia que os seres humanos fazem sobre si e também sobre as montanhas se alteraram no decorrer do tempo. Conforme Pinheiro (2006) o conhecimento antecede a 
atitude, e o modo como nos comportamos nos ambientes, depende na maioria das vezes de como os representamos pelo intermédio da nossa capacidade de resolver problemas, raciocinar e conceituar os objetos e ainda sujeitável a ação da nossa herança cultural. Desse modo, a herança cultural desenvolve estilos de vida distintos, interferindo no modo de vestir, comer, relacionar-se com as pessoas e com o ambiente no qual nos inserindo, modificando, portanto a nossa própria percepção e do ambiente, como podemos observar em relação à montanha.

\section{Metodologia}

Identificar o significado do ambiente que vivemos torna-se necessário, visto que as atitudes humanas são diferentes, interferindo na construção e relação dos indivíduos que vivem em sociedade. Diante dos inúmeros significados que as pessoas atribuem ao meio ambiente surgem indagações. Qual a percepção ambiental de alunos que vivem em espaços diferentes, como o rural e o urbano? Quais ações são feitas para melhorá-los? Temos interesse em distinguir os valores atribuídos ao espaço e as atitudes dos alunos frente aos problemas ambientais.

A pesquisa foi realizada em duas escolas de Ensino Básico situadas no município de Jaboticabal - SP. O instrumento para a coleta de dados foi o uso de um questionário. Fizeram parte desta pesquisa 44 alunos, de ambos os sexos, sendo 34 alunos da escola I, dos quais $15(44,1 \%)$ do sexo feminino e $19(55,8 \%)$ do sexo masculino. Já na escola II num total de 10 alunos, sendo que $02(20 \%)$ do sexo feminino e $08(80 \%)$ do sexo masculino. Os critérios estabelecidos para a escolha das escolas: a) são instituições de ensino do mesmo município; b) utilizam os mesmos materiais didáticos; c) os recursos humanos, financeiros e a infraestrutura são uniformes.

Foi aplicado um questionário, contendo 02 questões, uma aberta e uma semiaberta. A elaboração foi feita da seguinte forma: 1- Qual a importância dos rios e das matas? 2 - Você faz alguma ação para tentar melhorar o bairro onde vive? Justifique sua resposta. Os dados foram coletados entre os dias 29 de outubro a 01 de novembro de 2013. Teve como objetivo identificar nas respostas, a importância das águas dos rios, as matas ciliares e a relação com o ambiente urbano, e reconhecer as ações desempenhadas pelos alunos que são favoráveis a solucionar problemas ambientais no seu entorno.

Primeira questão: Qual a importância dos rios e das matas?

As respostas foram categorizadas em: percepção natural (habitat dos animais, preocupação com a natureza, sobrevivência no futuro, natureza preservada e desaparecimento dos animais) e percepção do ambiente natural/urbano (poluição, água potável, sustentável, saúde, alimento, renovável) (Tabela 1). 
Tabela 1: Organização das respostas dos alunos em relação à importância dos rios e das matas

\section{ESCOLA I}

ESCOLA II

\begin{tabular}{cccccc}
\hline $\begin{array}{c}\text { PERCEPC̃ÃO } \\
\text { AMBIENTAL }\end{array}$ & M & F & M & F & TOTAL \\
$\begin{array}{c}\text { Percepção } \\
\text { Natural }\end{array}$ & 10 & 8 & 3 & 1 & 24 \\
$\begin{array}{c}\text { Percepção } \\
\text { Natural/Urbano }\end{array}$ & 9 & 7 & 5 & 1 & 20 \\
TOTAL & 19 & 15 & 8 & 2 & 44 \\
\hline
\end{tabular}

De acordo com a Tabela 1 a escola I obteve maior número de resposta na categoria percepção natural. Nesta resposta constata-se que as águas dos rios, as matas e os animais são importantes para a manutenção da própria natureza como: "não devemos descuidar dos rios e das matas, pois os animais, as aves, e a própria natureza, utiliza as águas dos rios para sobreviverem"; "Sim é importante, porque os rios e as matas fazem parte da natureza e não pode destruir a natureza tem que preservar" ou "Por que os animais precisam dos rios e matas limpos, pois eles precisam de água, um ambiente mais limpo mais cheiroso, tem que ser limpo para as pessoas irem visitar rios e matas é melhor para todos e muito mais para a natureza e os animais". Identificamos nas respostas que os rios, as matas e os humanos são dissociados do meio ambiente, quer dizer, cada qual deve ter importância para o outro e não para todo.

Em seguida, a escola II obteve o maior número de resposta na categoria Percepção Natural/Urbano como: "É importante cuidar dos rios porque se você jogar lixo nele e cair esgoto nele e você entrar naquela água você vai prejudicar a sua própria saúde e as matas tem que ser preservadas para os animais e se você chegar por fogo naquele mato você vai matar muitos animais", "Importante pro mundo não ficar sujo não ter poluição os povos respirar o ar do meio ambiente não ficar cheio de sujeira os povos deve cuidar mais do meio ambiente, essas pessoas jogam lixo em todo lugar até no rio tem lixo na beira um monte devem cuidar mais do meio ambiente", ou "Sim, pois se não cuidar vai prejudicar os animais e o meio ambiente se se não cuidar das matas e dos rios vamos prejudicar nós e os animais ai disso tudo pode ocorrer doenças, poluição e etc...".

Percebe-se nas respostas que os julgamentos correlacionaram às ações humanas a destruição da natureza manifestando em primeiro lugar a importância de não poluir o ambiente. Nota-se que foram atribuídos ao meio ambiente valores naturais, sociais, políticos e econômicos, permitindo uma percepção mais abrangente da realidade no entorno no qual vivem. 
Somado os gêneros das duas escolas, a categoria percepção natural obteve o maior número de respostas (24). Tal percepção fragmenta o ambiente e, "[...] esquecemo-nos de observar o todo e compreender a dinâmica natural do planeta Terra" (OLIVEIRA; MACHADO, 2004, p.138). A categoria percepção natural/urbano recebeu o menor número de resposta entre alunos e alunas das duas escolas (20).

Atribui-se a falta de trabalhos críticos em que considere o plano diretor do munícipio um documento que deve nortear as ações humanas sobre o ambiente natural e urbano.

A escola II na categoria Percepção natural/urbano recebeu (5) respostas e a categoria percepção natural (3) para o mesmo gênero (Masculino). Observam-se percepções diferentes, embora prevaleça no entorno áreas naturais.

As escolas na maioria das vezes trabalham com projetos que distanciam os alunos do seu lugar. Mesmo nas escolas mais próximas do ambiente natural prioriza-se o trabalho com reciclagem, horta, plantio de árvore, entre outros trabalhos momentâneos da cultura urbana. Necessita-se de trabalhos perceptivos dos ambientes naturais e urbanos, para que alunos e alunas através dos seus sentidos possam compreender a importância de uma rua bem sinalizada, como também um rio bem cuidado.

Em outro trabalho, Souza e Pereira (2011) demonstram que as percepções de alunos tanto da área rural quanto da urbana apontam em sua maioria para uma visão antropocêntrica da relação homem e natureza, sobretudo, verificada nas respostas que identificam o homem como um ser determinista. Todos os espaços devem ser preenchidos pelo conhecimento dos humanos e sua missão é dominar outros da própria espécie, como também a natureza, mesmo que para isso seja necessário levar ao fim imensas florestas e exterminar milhares de pessoas. Coloca-se em prática um projeto que afasta o humano do próprio humano ao mesmo tempo da natureza e, cultua-se um novo paradigma ambiental pensando nas gerações futuras. Essas gerações desconhecidas são mais importantes do que a atual, contudo para que as florestas permaneçam existindo no futuro necessita-se da ação humana no presente, ou seja, uma tomada de consciência ambiental coletiva que priorize dentro das escolas um debate político sem esconder as reais causas da deterioração ambiental e humana.

Ribeiro e Affonso (2012) relatam que a experiência diária de alunos que vivem próximo a rio em área urbana tem influência direta na vida dos moradores. O rio poluído pode parecer anônimo, mas provoca uma reflexão, apesar de alunos e familiares participarem ativamente dessa ação. $O$ lugar perde sentido quando as pessoas e o poder público não o reconhecem como parte do todo. O município constituído por área urbana e natural não tem representatividade nos estudos das escolas municipais e estaduais, permitindo que o mesmo seja identificado apenas em projetos ambientais, que são oferecidos pela secretaria do meio ambiente, ora para manipular sucatas, 
outras vezes para comemorar dias específicos como da semana do meio ambiente e aniversário da cidade. Nas escolas o reflexo dessa desvalorização do município se encontra nos trabalhos e projetos desenvolvidos por meio da cumplicidade do Estado com o poder econômico, assim "[...] permite que a esfera educacional reproduza e cristalize os valores do discurso ideológico oficial, na medida em que se associa ao mercado e implementa programas voltados para a Pedagogia da Reciclagem nas escolas públicas" (LAYRARGUES, 2002, p. 20).

Segunda questão: Você faz alguma ação para tentar melhorar o bairro onde vive? Justifique sua resposta.

A Tabela 2 mostra que a necessidade de ações para melhoria do bairro é importante para a maioria dos alunos, não importando o sexo. A grande preocupação está na produção de resíduo descartado diariamente pelas residências como nas justificativas: "Mantenho minha casa limpa, não deixo água parada, separo plásticos e vidros de lixo orgânico. $E$ ter um bom comportamento e relação com a família", "Eu as vezes dentro do possível limpo meu quintal, retiro todas as sujeiras e também vejo se tem água parada pro foco da dengue, dentro do possível separo o lixo para reciclagem e eu economizo água" e "Sim, faço limpeza no quintal para não afetar o meio ambiente, pois cada sacolinha plástica demora anos para se desfazer no meio ambiente e com isto polui o meio ambiente".

Tabela 2: Organização das respostas dos alunos em relação às ações realizadas para melhorar o bairro.

\begin{tabular}{cccc}
\hline & ESCOLA I & TOTAL \\
\hline AÇÕES & $\mathbf{M}$ & $\mathbf{F}$ & 28 \\
SIM & 15 & 13 & 6 \\
NÃO & 4 & 2 & 34 \\
TOTAL & 19 & 15 & \\
\hline
\end{tabular}

Em relação às justificativas existem cobranças tanto do poder público quanto da sociedade civil organizada: "Por que quem tem que ver o lugar onde eu morro melhor é o prefeito, pois ele não faz nada por nenhum bairro por isso que eu não tento melhorar vem umas pessoas de outro bairro ou do próprio quebram as coisas, etc...". Ainda sobre as respostas que justificaram não realizar ações para melhorar o bairro outra nos chamou a atenção: "Por que no meu bairro não tem associação para isso". Essas justificativas apontam a necessidade da participação dos atores sociais nas decisões que dizem respeito às melhorias do lugar. De fato, as organizações sociais têm meios para iniciar as mudanças de âmbito natural, social, político e econômico e, sem dúvidas a sociedade civil constituída por atores sociais possui maior peso coletivo nas decisões e conquistas dentro da sociedade. 
Observa-se nas justificativas que mostram as ações realizadas, o destaque para a separação dos resíduos como uma importante atividade diária para melhoria do bairro. Entretanto, não aparece qualquer resposta que induza diminuir o consumo, prevalecendo a cultura hegemônica de base econômica. O principal objetivo das indústrias é fazer com que as pessoas consumam produtos que rapidamente sejam descartados, quer dizer, produtos que foram criados para serem transformados em resíduos. Assim, a reciclagem de materiais aparentemente é importante para o meio ambiente, mas contribui ainda mais para o aumento do consumo.

De acordo com Ribeiro e Affonso (2002) os principais responsáveis pelos cuidados de um rio são em primeiro lugar os moradores e em seguida 0 poder o público. Nota-se a importância dos trabalhos locais, onde boa parte da vida dos alunos e de seus pais ou responsáveis foram e ainda estão em processo de construção de uma identidade. O sujeito se identifica com seu lugar através das relações cotidianas com outras pessoas e com o ambiente físico. Não cuidar não pode ser considerado apenas o ato de poluir, mas também, o de não participar das decisões que afetam sua vida no bairro. Nesse sentido, a importância do aluno "[...] na minimização ou mesmo na resolução dos problemas socioambientais referentes ao seu espaço vivido é parte integrante do processo de sensibilização e constitui elemento fundamental para a mudança de mentalidade e de comportamento" (RIBIERO; AFFONSO, 2002, p.81).

A maioria dos alunos realiza alguma ação para tentar melhorar o bairro como: defender a separação dos resíduos domiciliares, economizar água e conscientizar os vizinhos para não jogar lixos na rua. "Não jogo lixo na rua $e$ ajudo meus vizinhos a cuidar do lugar onde mora, falando que não pode jogar lixo na rua."

A Tabela 3 mostra que do total de dez alunos, oito realizam alguma ação para melhorar o bairro. Observa-se que não houve uma disparidade entre as respostas das escolas no tocante as justificativas: "Não jogo lixo na rua como papel de bala coleto lixo e separo vários tipos de recicláveis". Esta escola está bem afastada da área mais urbanizada do município predominando um ambiente rural, cercada de fragmentos de matas, plantações e criações de animais.

Tabela 3: Organização das respostas dos alunos em relação às ações realizadas para melhorar o bairro.

\section{ESCOLA II}

\begin{tabular}{cccc}
\hline AÇÕES & M & F & TOTAL \\
SIM & 7 & 1 & 8 \\
NÃO & 1 & 1 & 2 \\
TOTAL & 8 & 2 & 10 \\
\hline
\end{tabular}


Nota-se que uma grande parcela das repostas também julga os resíduos um problema a ser resolvido e a reciclagem o melhor caminho. Nas justificativas das duas escolas as atitudes são influenciadas pela cultura do consumo e as condutas dos alunos são controladas pela economia, demonstrando a inexistência da esfera estatal e civil como interventores nessa realidade.

No trabalho de Philippe Layrargues (2002) intitulado, "O cinismo da reciclagem: o significado ideológico da reciclagem da lata de alumínio e suas implicações para a Educação Ambiental", a reciclagem não tem por objetivo limpar o planeta e ao mesmo tempo reverter o desmatamento, ao contrário, utiliza-se uma simbologia dotada de um alto grau de sensibilidade, para iludir as pessoas com produtos recicláveis a fim de aumentar o consumo e, assim gerar mais resíduo. Busca-se trocar um mundo insustentável pelo sustentável com forte esperança na reciclagem de materiais industrializados.

Para Layrargues (2002), esta prática que também se encontra na pedagogia escolar é resultado de estudos avançados da indústria mundial, a qual se manifesta como protetora dos direitos ambientais para todos os povos, mas que através das tecnologias imbuídas de racionalidade econômica busca na verdade aumentar os lucros por meio de produtos de fácil acesso com tempo de vida útil limitado.

No trabalho de Souza e Pereira (2011) uma parte dos alunos que vivem próximo às áreas naturais disse nunca ter participado de projetos ambientais com seus professores, porém o restante respondeu que desenvolveu atividades como: "[...] visita a nascente do rio, passeios pelas ruas da cidade $e$ pela borda do rio recolhendo o lixo nestes locais e principalmente o plantio de árvores" (SOUZA; PEREIRA, 2011, p. 38).

Observa-se que tais atividades são parecidas com a vida útil dos produtos, ou seja, são elaboradas para ter um rápido impacto no processo de aprendizagem e, que após alguns dias deve ser descartada pelos professores e alunos, sem efeitos profundos de transformação social. Necessita-se compreender o lugar de vivência em sua totalidade. As experiências dos alunos apenas com objetos empobrecem sua reflexão critica da realidade, a qual de tempos em tempos passa por um processo de transformação.

A escola deve reconhecer primeiramente seu papel na sociedade, para depois, transmitir em forma de projetos, conteúdos e estratégias pedagógicas diversas sua importância para o lugar. Se alunos não se sentem pertencentes ao bairro no qual vivem, significa que não reconhecem a função da escola naquele lugar. Para Ribeiro e Affonso (2002, p. 81) "O lugar constitui-se na base da reprodução da vida. É nele que se dá a reflexão sobre o cotidiano, a produção da existência social dos seres humanos e o local e o familiar revelam as transformações do mundo, permitindo identificá-las e explicá-las".

revista brasileira

educação ambiental 


\section{Conclusões}

Verificou-se que as percepções de meio ambiente diferiram entre as duas escolas. As respostas demonstraram que alunos que vivem mais próximos à natureza tem perspectiva diferente, daqueles que estão próximos à área urbanizada: percebem uma maior interação entre o ambiente natural e urbano. Outra questão que consideramos importante foram os valores atribuídos aos rios e matas justificando-os pelas condições: a primeira como fornecedores de matéria-prima e a segunda como áreas de lazer.

Nessa perspectiva percebem o ambiente pelas experiências anteriores, quer dizer, pela cultura da classe dominante que pratica uma hegemonia cultural. "[...] Poucas vezes aparecem oportunidades para expressar valores ambientais; os valores estão implícitos nas atividades econômicas das pessoas, comportamento e estilo de vida" (TUAN, 1980, p.78).

Outro aspecto importante diz respeito às ações que são feitas para melhorar o bairro. $\mathrm{Na}$ maioria das justificativas foram apontadas atitudes positivas em relação ao meio ambiente, não as compreendendo como meios de reprodução do sistema capitalista, que em um contexto global busca cada vez mais por uma eficiência econômica.

Também em uma visão de conjunto em relação às justificativas, identificou-se uma visão estética da natureza, como nos termos bela, feia e pura, demonstrando nessa perspectiva um contato superficial com os componentes rios e matas e isso pode ser esclarecido quando "[...] $\mathrm{Na}$ vida moderna, o contato físico com o próprio meio ambiente natural é cada vez mais indireto e limitado a ocasiões especiais" (TUAN, 1980, p.110).

\section{Referências}

HOLZER, W. Sobre paisagens, lugares e não-lugares. In: OLIVEIRA, L. (org.). Geografia, percepção e cognição do meio ambiente. Londrina: Edições Humanidades, 2006, p.313.

LAYRARGUES, P.P. O cinismo da reciclagem: o significado ideológico da reciclagem da lata de alumínio e suas implicações para a Educação Ambiental. In: LAYRARGUES, P.P.(org). Educação Ambiental: repensando o espaço da cidadania. São Paulo: Cortez, p. 179-220, 2002.

OLIVEIRA, L; MACHADO, L.M.C.P. Percepção, cognição, dimensão ambiental e desenvolvimento com sustentabilidade. In: VITTE, A.C; GUERRA, A.J.T. Reflexões sobre a Geografia física no Brasil. Rio de Janeiro: Bertrand Brasil, 2004, p. 129-152.

PINHEIRO, J. Q. Mapas cognitivos de mundo, tempo na experiência ambiental, lugar e sustentabilidade. In: OLIVEIRA, L. (org.). Geografia, percepção e cognição do meio ambiente. Londrina: Edições Humanidades, 2006, p.313. 
RIBEIRO, C.R.; AFFONSO, E.P. Avaliação da percepção ambiental de alunos do ensino fundamental residentes na bacia hidrográfica do córrego São PedroJuiz de Fora/MG-doi: 10.4025/bolgeogr. v30i2. 10077. Boletim de Geografia, v. 30, n. 2, p. 73-85, 2012.

SOUZA, P.P.S.; PEREIRA, J L.G. Representação social de meio ambiente e Educação Ambiental nas escolas públicas de Teófilo Otoni-MG. Revbea, Rio Grande, v. 6, p. 35-40, 2011.

TUAN, Y.F. Topofilia: um estudo da percepção, atitudes e valores do meio ambiente. Tradução de Lívia de Oliveira. São Paulo: DIFEL, 1980.

TUAN, Y.F. Espaço e lugar: a perspectiva da experiência. Tradução de Lívia de Oliveira. Londrina: Eduel, 2013, p.248. 